\title{
The Effect of Applying DOPS on BDS Students' Orthodontic Skills: A Quasi-Experimental Study
}

\author{
Muhammad Azeem ${ }^{1}$ \\ Javed Iqbal ${ }^{2}$ \\ Arfan Ul $\mathrm{Haq}^{3}$
}

\author{
BDS, FCPS \\ BDS, M.Phil \\ MDS, FCPS, MCPS, BDS
}

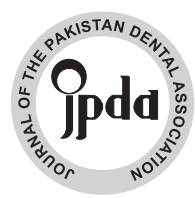

OBJECTIVE: To compare the effectiveness of two teaching methods i.e. Directly Observed Procedural Skills (DOPS) and traditional teaching of procedural skills in Orthodontics to the BDS dental students.

METHODOLOGY: Present study was conducted on 30 BDS final year students of Dental Section-Faisalabad Medical University. Dental students were divided into two groups i.e. 15 students in the DOPS group and 15 students in the traditional teaching group. The Multiple choice questions (MCQs) tests were taken before and after the procedural skills teaching from both the groups. The cumulative scores were calculated before and after the teaching of procedural skills in both the groups. Student paired t test was used for comparison of data.

RESULTS: Results showed that for all the taught orthodontic procedural skills, post-test scores were found to be significantly higher in DOPS group in comparison with the post-test scores in traditional teaching group. $(p>0.05)$ CONCLUSION: The teaching of orthodontic procedural skills to BDS students is more effective using DOPS than the traditional teaching of procedural skills.

KEY WORDS: Orthodontic skills, student, dops.

HOW TO CITE: Azeem M, Iqbal J, Haq UA. The effect of applying DOPS on BDS students' orthodontic skills: a quasiexperimental study. J Pak Dent Assoc 2019;28(1):18-21.

DOI: https://doi.org/10.25301/JPDA.281.18

Received: 10 August 2018, Accepted: 27 October 2018

\section{INTRODUCTION}

$\mathrm{D}$ irectly Observed Procedural Skills (DOPS) is effective teaching tool for teaching of essential procedural skills at undergraduate and postgraduate level. ${ }^{1}$ It usually consists of 5 minutes task followed by 5 minutes feedback to students. Therefore it improves performance of students and increases interaction between teachers and students. In comparison, traditional methods of teaching essential procedural skills are devoid of interaction between teachers and students as no feedback session is involved in it. ${ }^{2,3}$

Studies have been conducted on evaluation of effectiveness of DOPS in different specialties of medical and dentistry. Shahgheibi et al. conducted a study on evaluation of effectiveness of DOPS in maternity units. ${ }^{4}$

1. Assistant Professor, Department of Orthodontics, Dental Section-Faisalabad Medical University, Pakistan.

2. Associate Professor, Department of Oral Biology, Dental Section-Faisalabad Medical University, Pakistan.

3. Principal, Professor \& Head, Department of Orthodontics, Dental Section-Faisalabad Medical University, Pakistan.

Corresponding author: "Dr. Muhammad Azeem”< dental.concepts@hotmail.com >
Haq et al. conducted a study on evaluation of effectiveness of DOPS in Opthalmology at undergraduate levels. ${ }^{5}$ This method of skill assessment is not limited to postgraduate residents. Bazrafkan et al. did comparison of the assessment of dental students' laboratory performance. ${ }^{6}$

Very few studies have been conducted on evaluation of effectiveness of DOPS in Orthodontics at undergraduate levels. ${ }^{6}$ Most of the studies didn't compare DOPS with other existing traditional teaching methods.

Following this rationale, the objective of present study was to compare the effectiveness of two teaching methods i.e. Directly Observed Procedural Skills (DOPS) and traditional teaching of procedural skills in Orthodontics to dental students. DOPS may enhance learning capacity of procedural skills in orthodontics at the undergraduate level. DOPS ensures that students are given feedback based on direct observation so as to improve the orthodontic skills of students at undergraduate level.

\section{METHODOLOGY}

This Quasi-Experimental Study, was designed and conducted 
at Dental Section-Faisalabad Medical University, Faisalabad.

On 30 BDS final year students after taking informed consent and institutional ethical board approval (010/DFMU) of Dental Section-Faisalabad Medical University. The sample size of 30 was based on the number of BDS final year students that gave consent of take part in the present study.

Dental students were divided into two groups i.e. 15 students in the DOPS group and 15 students in the traditional teaching group. The distribution was made with assurance to distribute students of similar knowledge in both the groups based on the marks in the third professional BDS exam. So students were statistically same in both the groups at baseline.

Obtaining informed consent from the orthodontic patients and doing wire work (Labial Bow) on plaster models were the skills selected for the study. The faculty of the orthodontic department was given orientation to the DOPS and also in the skills regarding giving good feedback by medical educationists and subject experts. A brief orientation was also provided to the students regarding DOPS. The Multiple choice questions (MCQs) tests were taken before and after the procedural skills teaching from both the groups. Based on the expert opinion, DOPS structured teaching scheme was devised and grading/marking form for each procedure was created. On average it took 7 minutes to complete the procedure on each student i.e. 5 minutes for students to complete the task followed by 2 minutes feedback to the students. The cumulative scores were calculated before and after the teaching of procedural skills in both the groups.

\section{DATA ANALYSIS}

The mean scores and standard deviations were calculated before and after the teaching of procedural skills in both the groups. Student paired t test was used for comparison of data between the two groups. The level of significance was determined at $\mathrm{p} \leq 0.05$.

\section{RESULTS}

Present study was conducted on 30 BDS final year students $(\mathrm{N}=30)$. There were 12 female and 3 male students in each group.

Results showed that at the baseline, for all the taught orthodontic procedural skills, pre-test scores were found to be significantly similar in DOPS and in traditional teaching group $(\mathrm{p}>0.05)($ Table 1$)$.

Table 1: Comparison $(\mathrm{N}=30)$

\begin{tabular}{|l|c|c|c|c|c|}
\hline \multicolumn{1}{|c|}{ Groups } & Mean & $\mathrm{N}$ & $\begin{array}{c}\text { Std. } \\
\text { Deviation }\end{array}$ & $\begin{array}{c}\text { Std. Error } \\
\text { Mean }\end{array}$ & P value \\
\hline Pretest ConsentTraditional group & 3.33 & 30 & .578 & .143 & \\
\hline Pretest Consent DOPS group & 3.42 & 30 & .634 & .176 & $>.05$ \\
\hline Pretest Labial bow Traditional group & 3.23 & 30 & 1.167 & .221 & \\
\hline Pretest Labial bow DOPS group & 3.33 & 30 & .756 & .165 & $>.05$ \\
\hline Pretest Consent Traditional group & 3.49 & 30 & .768 & .126 & \\
\hline Post test Consent Traditional group & 5.11 & 30 & .674 & .154 & $<.05$ \\
\hline Pretest Consent DOPS group & 3.23 & 30 & .478 & .125 & \\
\hline Post test Consent DOPS group & 5.97 & 30 & .709 & .196 & $<.05$ \\
\hline Pretest Labial bow Traditional group & 3.64 & 30 & 1.234 & .211 & \\
\hline PostTest Labial bow Traditional group & 4.64 & 30 & .749 & .178 & $<.05$ \\
\hline Pretest Labial bow DOPS group & 3.57 & 30 & .790 & .167 & \\
\hline Post test Labial bow DOPS group & 5.92 & 30 & .743 & .156 & $<.05$ \\
\hline Post test Consent Traditional group & 4.23 & 30 & .678 & .169 & \\
\hline Post test Consent DOPS group & 5.97 & 30 & .775 & .193 & $<.05$ \\
\hline PostTest Labial bow Traditional group & 4.12 & 30 & .783 & .169 & \\
\hline Post test Labial bow DOPS group & 6.12 & 30 & .799 & .170 & $<.05$ \\
\hline
\end{tabular}


Results showed that for all the taught orthodontic procedural skills, post-test scores were found to be significantly higher in DOPS group in comparison with the post-test scores in traditional teaching group $(\mathrm{p}<0.05)$ (Table 1).

\section{DISCUSSION}

Workplace based assessment is of the effective way of enhancing educational impact and to improve learning and teaching. ${ }^{7-9}$ DOPS focuses on technical, operative and procedural skills for basic procedures. ${ }^{10}$ The objective of present study was to compare the effectiveness of two teaching methods i.e. Directly Observed Procedural Skills (DOPS) and traditional teaching of procedural skills in Orthodontics to dental students.

Obtaining informed consent from orthodontic patients, and doing wire (Labial bow) ${ }^{11}$ on plaster models were the skills selected for the study. These procedures were selected because of importance of procedures at undergraduate level and observer could mark student's performance stepwise. There were 12 female and 3 male students in each group in the present study. The equal distribution of male and female students in each group was not possible because of induction of maximum female students in BDS while entrance in dental colleges on merit.

Results in the present study showed that at the baseline, for all the taught orthodontic procedural skills, pre-test scores were found to be significantly similar $(p>0.05)$ in DOPS and in traditional teaching group, this may be due to the fact that the distribution was made with an assurance to distribute students of equal knowledge in both the groups based on the marks in third professional BDS exam. So students were statistically same in both the groups at baseline. The findings of present study are in agreement with the findings of study by Inam et al., where difference among undergraduate students in DOPS group and traditional group was insignificant. $^{5}$

Results showed that for all the taught orthodontic procedural skills, post-test scores were found to be significantly higher $(\mathrm{p}<0.05)$ in DOPS group in comparison with the post-test scores in traditional teaching group. Thus it was found that the teaching of orthodontic procedural skills to BDS students is more effective using DOPS than the traditional teaching of procedural skills. The findings of present study are in agreement with the findings of study by Shahgheibi et al., where DOPS were found to be very useful in increasing students' skill learning. ${ }^{4}$ The findings of present study are also in agreement with the findings of study by Inam et al., where undergraduate students in DOPS group performed significantly better than their counterparts in traditional group. ${ }^{5}$ The findings are also in accordance with the findings of study by Bazrafkan et al., where findings revealed that DOPS is a useful tool for assessing dental students' dental laboratory skills. ${ }^{6}$

In general, current evidence showed that workplace based assessment is not yet sufficient in terms of reliability but highly valid. ${ }^{12-16}$ DOPS is not widely used in undergraduate dental education in Pakistan, but in light of findings of current study DOPs may enhance learning capacity of procedural skills in orthodontics at undergraduate level. However there are certain disadvantages of DOPS, such as, financial cost, time cost, and training of trainers and trainees and feasibility issues. ${ }^{17-19}$

Limitation of present study is small sample size, for which future large scale studies are suggested to validate the results of current study.

\section{CONCLUSION}

The teaching of orthodontic procedural skills to BDS students is more effective using DOPS than the traditional teaching of procedural skills.

\section{CONFLICT OF INTEREST}

None to declare

\section{REFERENCES}

1. Hatala R, Cook DA, Zendejas B, Hamstra SJ, Brydges R. Feedback for simulation-based procedural skills training: a meta-analysis and critical narrative synthesis. Adv Health Sci Educ. 2014;19:251-72. https://doi.org/10.1007/s10459-013-9462-8

2. LaDonna KA, Hatala R, Lingard L, Voyer S, Watling C. Staging a performance: learners' perceptions about direct observation during residency. Med Educ. 2017;51:498-10.

https://doi.org/10.1111/medu.13232

3. Modi JN, Gupta P, Singh T. Competency-based medical education, entrustment and assessment. Indian Pediatr. 2015;52:413-20. https://doi.org/10.1007/s13312-015-0647-5

4. Shahgheibi SH, Pooladi A, BahramRezaie M, Farhadifar F, Khatibi R. Evaluation of the Effects of Direct Observation of Procedural Skills (DOPS) on clinical externship students' learning level in obstetrics ward of kurdistan university of medical sciences. J Med Educ. 2009 25;29-33.

5. Inam UH, Jamil B, Durrani M. Procedural skills; learning of procedural skills in ophthalmology through directly observed procedural skills (DOPS) or traditional methods; a randomized controlled trial. Professional Med J 2018; 25:1207-12.

6. Bazrafkan L, Shokrpour N, Torabi KI. Comparison of the Assessment 
of Dental Students' Laboratory Performance through MCQ and DOPS Methods. J Med Educ. 2009;13:3-8

7. Kogan JR, Conforti LN, Bernabeo E, Iobst W, Holmboe E. How faculty members experience workplace-based assessment rater training: a qualitative study. Med Educ. 2015;49:692-08.

https://doi.org/10.1111/medu.12733

8. Massie J, Ali JM. Workplace-based assessment: a review of user perceptions and strategies to address the identified shortcomings. . Adv Health Sci Educ. 2016;21:455-73.

https://doi.org/10.1007/s10459-015-9614-0

9. Jain MD, Tomlinson GA, Lam D, Liu J, Damaraju D, Detsky AS, Devine LA. Workplace-based assessment of internal medicine resident diagnostic accuracy. J Grad Med Educ.2014;6(3):532-35. https://doi.org/10.4300/JGME-D-13-00431.1

10. Augustine K, McCoubrie P, Wilkinson JR, McKnight L. Workplacebased assessment in radiology - where to now? Clin Radiol 2010; 65: 325-32.

https://doi.org/10.1016/j.crad.2009.12.004

11. Mahmood A, Nazir R. A Structured Programme for Post Graduate Training in Orthodontics. Pak Orthod J. 2014;6:87-108.

12. Sia JY, Harrison JE. Trainers' and trainees' perceptions of workplacebased assessment in orthodontics. J Orthod. 2015;42:284-300. https://doi.org/10.1179/1465313315Y.0000000015

13. McKenzie S, Burgess A, Mellis C. Interns reflect: the effect of formative assessment with feedback during pre-internship. Adv Health
Sci Educ Theory Pract. 2017;8:51-56. https://doi.org/10.2147/AMEP.S114480

14. General Medical Council. Workplace-Based Assessment: A Guideline for Implementation. London: GMC, 2010.

15. Siau K, Levi R, Howarth L, Broughton R, Feeney M, Beales IL, Tzivinikos C, Narula P. Validity Evidence for Direct Observation of Procedural Skills in Paediatric Gastroscopy. J Pediatr Gastroenterol Nutr. 2018;67:111-16

https://doi.org/10.1097/MPG.0000000000002089

16. Siau K, Dunckley P, Valori R, Feeney M, Hawkes ND, Anderson JT, Beales IL, Wells C, Thomas-Gibson S, Johnson G. Changes in scoring of Direct Observation of Procedural Skills (DOPS) forms and the impact on competence assessment. Endoscopy. 2018;50:770-78. https://doi.org/10.1055/a-0576-6667

17. Erfani Khanghahi M, Ebadi Fard Azar F. Direct observation of procedural skills (DOPS) evaluation method: Systematic review of evidence. Med J Islam Repub Iran. 2018;32:254-61.

https://doi.org/10.14196/mjiri.32.45

18. Amini A, Shirzad F, Mohseni MA, Sadeghpour A, Elmi A. Designing Direct Observation of Procedural Skills (DOPS) Test for Selective Skills of Orthopedic Residents and Evaluating Its Effects from Their Points of View. Res Dev Med Educ. 2015;4:147-52. https://doi.org/10.15171/rdme.2015.026

19. Singh T, Kundra S, Gupta P. Direct observation and focused feedback for clinical skills training. Indian Pediatr. 2014;51:713-17. https://doi.org/10.1007/s13312-014-0487-8 